\title{
summary
}

\section{Consistent increase in enamel erosion literature but quality has not changed with time}

Maupomé G, Ray JM. Structured review of enamel erosion literature (1980-1998): a critical appraisal of experimental, clinical and review publications. Oral Dis 2000; 6:197-207

Objective To obtain a census of the methods used to measure enamel erosion, to establish factors likely to affect erosion and compare critically research approaches.

Data sources Medline and Current Contents (1980-1998). No hand searching was undertaken.

Study selection Experimental and research papers in English with blinding and controls described were included. Case reports, editorial and clinically descriptive studies were excluded, as were papers from non-biomedical journals.

Data extraction and synthesis Papers were assessed using a standardised scoring sheet and classified using a modified version of the Canadian Task Force on Periodic Health Examination system.

Results Of 735 papers identified, 85 were included in the review. Mean score and evidence levels are shown in Table 1.
Table 1 Mean score and evidence level of papers included

\begin{tabular}{ccc}
\hline Evidence-level & Number of studies & Mean score \\
\hline I & 2 & 34 \\
II a \& b & 15 & 26.4 \\
III a \& b & 46 & 24.2 \\
IV & 9 & 25.2 \\
\hline
\end{tabular}

Conclusions A consistent increase in the body of knowledge regarding enamel erosion is seen but the quality of research design has not changed with time.

Partially funded by the S. Wah Leung Endowment Fund, Vancouver, British Colombia, Canada.

Address for reprints: Dr Gerardo Maupomé, Department of Oral Health Sciences, Faculty of Dentistry, University of British Columbia, 2199 Westbrook Mall, Vancouver BC V6T 1ZY, Canada.

E-mail: maupome@unix.ubc.ca

\section{Commentary}

Dental erosion is nothing new although, until recently, the literature on this topic has been dominated by case reports. Thelast few decades, however, have seen an expansion in the dental literature on the epidemiology of dental erosion. This has been followed closely in number by papers that purport to show a causal relationship with the factors thought to be related to the increased prevalence of such wear. There is, more recently, an awareness that erosion per se is difficult to assess in isolation from other aspects of tooth wear and second that, like dental caries, erosion is multifactorial in its aetiology.

As the authors describe, the increase in literature about erosion, or, at least, tooth wear has been exponential, but in the 2 years since this review was completed there has been a focusing of research ${ }^{1}$ in acknowledgement of the problems highlighted in this review: poor research design and inappropriate statistical analysis. The other major omission in this field is of course sufficient evidence to quantify change over time. In this area the refinement of the indices available to measure such increments is vital if the inadequacies described in this review are not to be perpetuated. Although it highlights these conundrums, having omitted a hand search and having adopted the inclusion criteria that it did, the paper has in a way foregone the opportunity to explore a body of relevant knowledge and, by doing so, underrated the efforts of researchers to refine the science. $^{2-5}$

In part, the fault lies not with the authors of the individual studies reviewed but with the system; funding bodies are very focused on assessing outcomes from care and positively endorsing the use of an index to assess such outcomes. The use of the Index of Orthodontic Treatment Need (IOTN) in orthodontics is one such example. This has not been the case with tooth wear, despite the potential for its management to incur high initial treatment and maintenance costs for both the patient and the State. With an increasingly dentate population ${ }^{5}$ the development of an index that incorporates consideration of the extent of wear, of whatever type, as well as treatment difficulties, patient symptoms and possibly the patient's desire for treatment, is timely. The health departments in the United Kingdom are to be congratulated for enabling researchers, working on large-scale epidemiological surveys commissioned by the Government, to use the data thus collected. The nuances of the findings then can be brought to the attention of those in primary dental care who are paid to treat the ravages of tooth wear. ${ }^{6}$ What should follow is a commitment to refining the index developed for this purpose, incorporating the elements described above, to be truly useful in both research and clinical practice.

1. Embery $G$, Orchardson R, Edgar $M$, Addy $M$ (Eds). Tooth Wear and Sensitivity. London: Martin Dunitz, 2000.

2. Hinds K, Gregory J. National Diet and Nutrition Survey: Children Aged 11/2-41/2 Years. Volume 2: Report of the Oral Health Survey. London: HMSO, 1995.

3. O'Brien M. Children's Dental Health 1993. London: HMSO, 1995.

4. Walker A, Gregory J, Bradnock G, Nunn JH, White D. National Diet and Nutrition Survey: Young People 4 to 18 Years. Volume 2: Report of the Oral Health Survey. London: The Stationery Office, 2000.

5. Kelly M, Steele J, Bradnock G, et al. Adult Dental Health. Oral Health in the United Kingdom 1998. London: The Stationery Office, 2000.

6. Nunn JH, Morris AJ, Pine CM, Pitts NBB, Bradnock $G$, Steele J. Oral disease in adults in the UK in 1998 and implications for the future. Br Dent J 2000; 189:639-644.

June Nunn Child Dental Health, Newcastle upon Tyne University, UK 